02

\title{
Фотолиз диазокрасителя в водных растворах нитратов металлов
}

\author{
(c) Н.А. Волкова ${ }^{1}$, С.К. Евстропьев ${ }^{1}$, О.В. Истомина ${ }^{2}$, Е.В. Колобкова ${ }^{1,2}$ \\ ${ }^{1}$ Университет ИТМО, \\ 197101 Санкт-Петербург, Россия \\ ${ }^{2}$ Санкт-Петербургский государственный технологический институт (технологический университет), \\ 190013 Санкт-Петербург, Россия \\ e-mail: nadezhdav23@gmail.com
}

Поступила в редакцию 17.11.2017 г.

Исследован фотолиз диазокрасителя Chicago Blue Sky. Экспериментально показано, что присутствие нитратов металлов в водных растворах изменяет механизм фотолиза и резко увеличивает его скорость.

DOI: $10.21883 /$ OS.2018.04.45746.266-17

\section{Введение}

На протяжении многих лет взаимодействие органических красителей со светом является предметом интенсивных исследований, что обусловлено как широким практическим применением этих материалов, так и решением фундаментальных проблем взаимодействия излучения с веществом.

В последние годы большой интерес вызывают исследования, связанные с взаимодействием солнечного света с различными материалами. Это обусловлено все возрастающим практическим использованием солнечного излучения в энергетике, экологии, разработкой различных фоточувствительных „умных“ материалов и покрытий. Много работ посвящено использованию светового излучения для разложения различных органических загрязнений в водной среде или на поверхности различных твердых тел [1-10].

Широко распространенным методическим приемом для оценки фотокаталитических свойств материалов является изучение фотолиза контролируемых количеств хорошо известных органических красителей, таких как Methylene Blue, Chicago Sky Blue, Methyl Orange [4,6-10]. Спектральные свойства водных растворов диазокрасителя Chicago Blue Sky (структура красителя приведена на рис. 1) описаны в литератуpe [11]. Растворы этого красителя используются для оценки фотокаталитических свойств различных материалов $[7-10,12]$. Вместе с тем эти растворы, а также их<smiles>COc1cc(C)ccc1N=Nc1ccc2c(S(=O)(=O)O[Na])cc(S(=O)(=O)O[Na])c(N)c2c1O</smiles>

Pис. 1. Структура молекулы диазокрасителя Chicago Sky Blue (CSB). смеси с растворами других веществ, широко используемых в промышленности, являются объектом экологических исследований, и разработка методов очистки воды от этого красителя является актуальной [10].

Известно, что фотолиз водных растворов является эффективным способом разложения органических красителей [10]. Однако при наличии в растворах помимо красителя других веществ эффективность и механизм фоторазложения красителя может существенно измениться. Целью настоящей работы являлось исследование процесса фотолиза диазокрасителя в водных растворах, содержащих нитраты металлов.

\section{Материалы и методика эксперимента}

В качестве объектов исследования в работе использовались водные растворы нитратов цинка и иттрия, а также водный раствор органического красителя Chicago Sky Blue 6B (CSB) (Sigma Aldrich). Предварительно взвешенные навески порошков растворялись при перемешивании в дистиллированной воде. Полученные растворы содержали $0.21 \mathrm{M} \mathrm{Zn}\left(\mathrm{NO}_{3}\right)_{2}, 0.13 \mathrm{M} \mathrm{Y}\left(\mathrm{NO}_{3}\right)_{3}$, $5.4 \cdot 10^{-4} \mathrm{M}$ CSB и смешивались между собой или при добавлении воды в заданных пропорциях. Измерения спектров поглощения растворов осуществлялось в кварцевых кюветах на спектрофотометре Perkin-Elmer Lambda 650. Облучение растворов осуществлялось ртутной лампой высокого давления ДРТ-240.

\section{Результаты эксперимента и их обсуждение}

На рис. 2, а представлены спектры поглощения использованных нами водных растворов CSB различной концентрации без добавок нитратов металлов. Влияние концентрации красителя на форму спектров поглощения хорошо согласуется с опубликованными ранее результатами [11].

На рис. 2, $b$ приведены спектры поглощения различных водных растворов нитратов цинка и иттрия. 

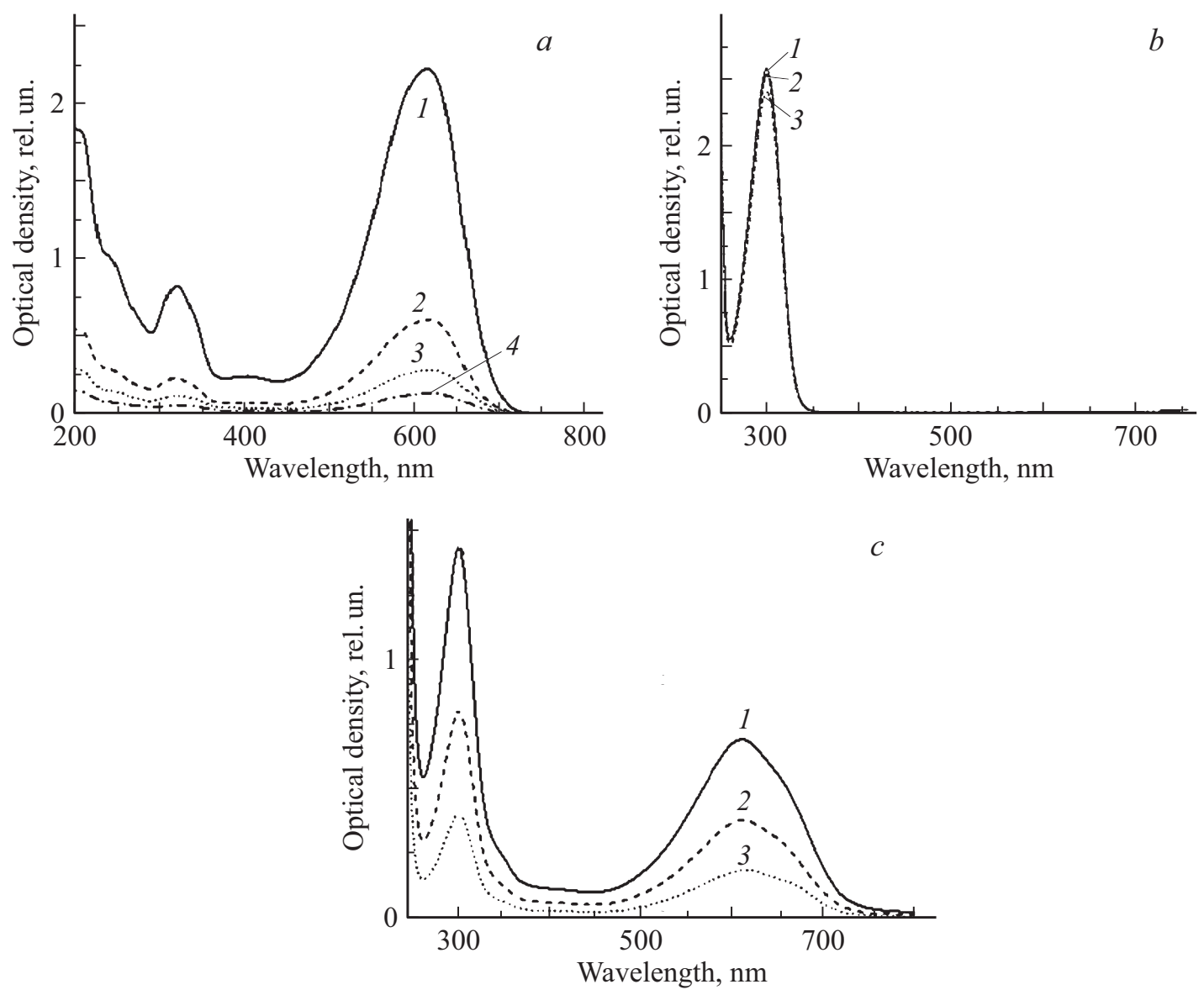

Рис. 2. (a) Спектры поглощения водных растворов CSB, концентрация растворов $4.3 \cdot 10^{-5} \mathrm{M}(1), 8.6 \cdot 10^{-6} \mathrm{M}(2)$, $4.3 \cdot 10^{-6} \mathrm{M}(3), 2.2 \cdot 10^{-6} \mathrm{M}(4)$. (b) Спектры поглощения водных растворов нитрата цинка и иттрия: $(1)$ раствор $\mathrm{Y}\left(\mathrm{NO}_{3}\right)_{3}$ $(0.13 \mathrm{M}) ;(2)$ раствор, содержащий $\mathrm{Zn}\left(\mathrm{NO}_{3}\right)_{2}\left(1.6 \cdot 10^{-2} \mathrm{M}\right)$ и $\mathrm{Y}\left(\mathrm{NO}_{3}\right)_{3}(0.12 \mathrm{M}) ;(3)$ раствор, содержащий $\mathrm{Zn}\left(\mathrm{NO}_{3}\right)_{2}\left(8 \cdot 10^{-2} \mathrm{M}\right)$ и $\mathrm{Y}\left(\mathrm{NO}_{3}\right)_{3}\left(6.5 \cdot 10^{-2} \mathrm{M}\right)$. (c) Спектры поглощения водных растворов CSB, содержащих нитрат цинка: концентрация CSB $4.3 \cdot 10^{-5} \mathrm{M}(1), 8.6 \cdot 10^{-6} \mathrm{M}(2), 4.3 \cdot 10^{-6} \mathrm{M}(3), 2.2 \cdot 10^{-6} \mathrm{M}(4) ;$ концентрация $\mathrm{Zn}\left(\mathrm{NO}_{3}\right)_{2} \quad 0.15 \mathrm{M}(1), 7.5 \cdot 10^{-2} \mathrm{M}(2)$, $3.8 \cdot 10^{-2} \mathrm{M}(3)$.

В УФ части спектров хорошо видна полоса поглощения анионов $\mathrm{NO}_{3}^{-}$с $\lambda_{\max }=301 \mathrm{~nm}$. Интенсивность этой полосы поглощения и вид спектров соответствуют литературным данным [3]. Спектры поглощения смешанных растворов, содержащих CSB и нитраты металлов, приведены на рис. 2, $b$. По сравнению со спектрами, приведенными на рис. 1, $a$, в спектрах смешанных растворов наблюдается заметно большее поглощение света в области 280-320 nm, что обусловлено перекрытием полос поглощения красителя (рис. $2, a$ ) и анионов $\mathrm{NO}_{3}^{-}$ (рис. 2,b).

Кроме того, наблюдается различие в форме интенсивной полосы поглощения красителя в видимой области спектра. На спектре поглощения раствора, содержащего нитраты металлов, помимо максимума с $\lambda_{\max }=608 \mathrm{~nm}$ виден перегиб спектральной зависимости в области $670 \mathrm{~nm}$. Аналогичного перегиба в спектре раствора, не содержащего краситель, не наблюдается.

При содержании CSB более $10^{-7}-10^{-6} \mathrm{M}$ в водных растворах могут происходить процессы межмолекуляр- ного взаимодействия и образования димеров и тримеров из молекул красителя $[11,12]$. При этом интенсивная полоса поглощения красителя в видимой области спектра представляет собой суперпозицию полос поглощения как мономеров, так и указанных структур, сформированных из молекул CSB [11]. Еще более сильно процессы структурообразования могут развиваться в присутствии ионов металлов, способных к формированию комплексов с азокрасителями [13]. Можно предположить, что наблюдаемые некоторые различия в формах интенсивной полосы поглощения CSB в видимой части спектра (рис. $1, a, b)$ связаны с различной степенью межмолекулярного взаимодействия в растворах с добавками нитратов цинка и иттрия и без этих добавок.

Характерные изменения спектров поглощения водных растворов CSB различной концентрации в процессе облучения светом ртутной лампы ДРТ-240 представлены на рис. 3,a. Видно, что в процессе облучения наблюдается уменьшение интенсивности поглощения света растворами, что отражает процесс фотолиза красителя. 

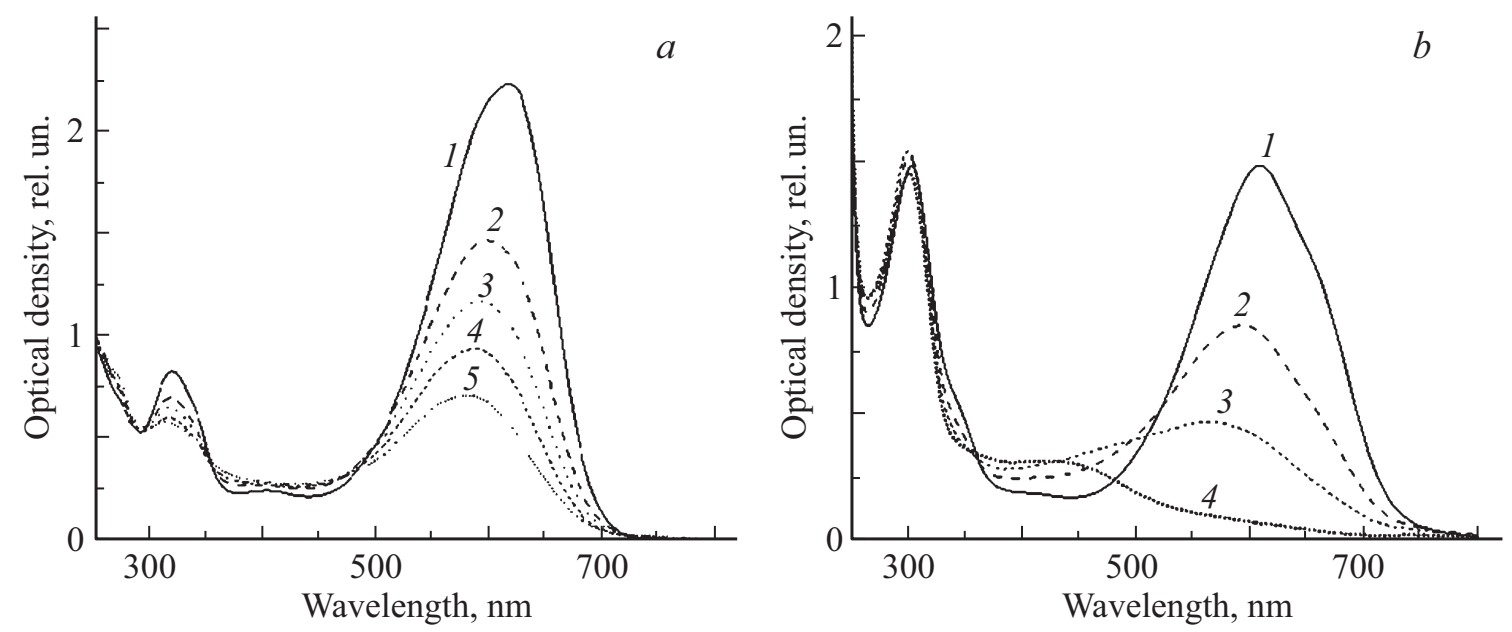

Рис. 3. Изменения спектров поглощения растворов при облучении ртутной лампой высокого давления. (a) Раствор CSB $\left(4.3 \cdot 10^{-5} \mathrm{M}\right)$; продолжительность облучения: $0(1), 15(2), 30(3), 45(4), 60 \mathrm{~min}(5)$. (b) Раствор CSB $\left(4.3 \cdot 10^{-5} \mathrm{M}\right)$, содержащий нитрат цинка (концентрация $0.16 \mathrm{M}$ ) и нитрат иттрия (концентрация $0.13 \mathrm{M}$ ); продолжительность облучения: 0 (1), 5 (2), 10 (3), $15 \min (4)$.

В результате облучения этих растворов наблюдается некоторый сдвиг максимума наиболее интенсивной полосы поглощения с 616 до $578 \mathrm{~nm}$.

Сопоставление рис. 2, $a$ и 3, $a$ показывает, что характер изменений, наблюдаемых при фотообработке (форма спектров и положения максимума полосы поглощения в видимой части спектра), в целом соответствует уменьшению содержания красителя в водных растворах. Однако обращает на себя внимание тот факт, что в отличие от видимой части спектра при фотообработке не наблюдается снижения поглощения света растворами в УФ области спектра при $\lambda<300 \mathrm{~nm}$. Наблюдаемые различия в спектрах, приведенных на рис. $1, a$ и $2, a$, можно объяснить поглощением света в УФ области спектра продуктами фотолиза красителя в растворах, подвергнутых фотообработке.

Изменения в спектрах поглощения, наблюдаемые при облучении смешанных растворов, показаны на рис. $3, b$. Наблюдается быстрое уменьшение интенсивности полосы поглощения красителя в видимой части спектра, сопровождающееся резким смещением положения ее максимума в коротковолновую область спектра. Сопоставление рис. $3, a$ и $3, b$ позволяет сделать вывод о том, что присутствие нитратов металлов в водном растворе существенно изменяет характер и продукты фотолиза красителя. Так же как и в спектрах, приведенных на рис. 3, $a$, в спектрах фотообработанных растворов CSB, содержащих нитраты металлов, не наблюдается уменьшение поглощения света в УФ области спектра.

Фотографии (on line), приведенные на рис. 4, иллюстрируют характер изменения внешнего вида водных растворов CSB под действием излучения ртутной лампы. Видно, что при облучении растворов, не содержащих нитраты металлов, наблюдается их постепенное обесцвечивание и их исходно синий цвет сменяется бледно-

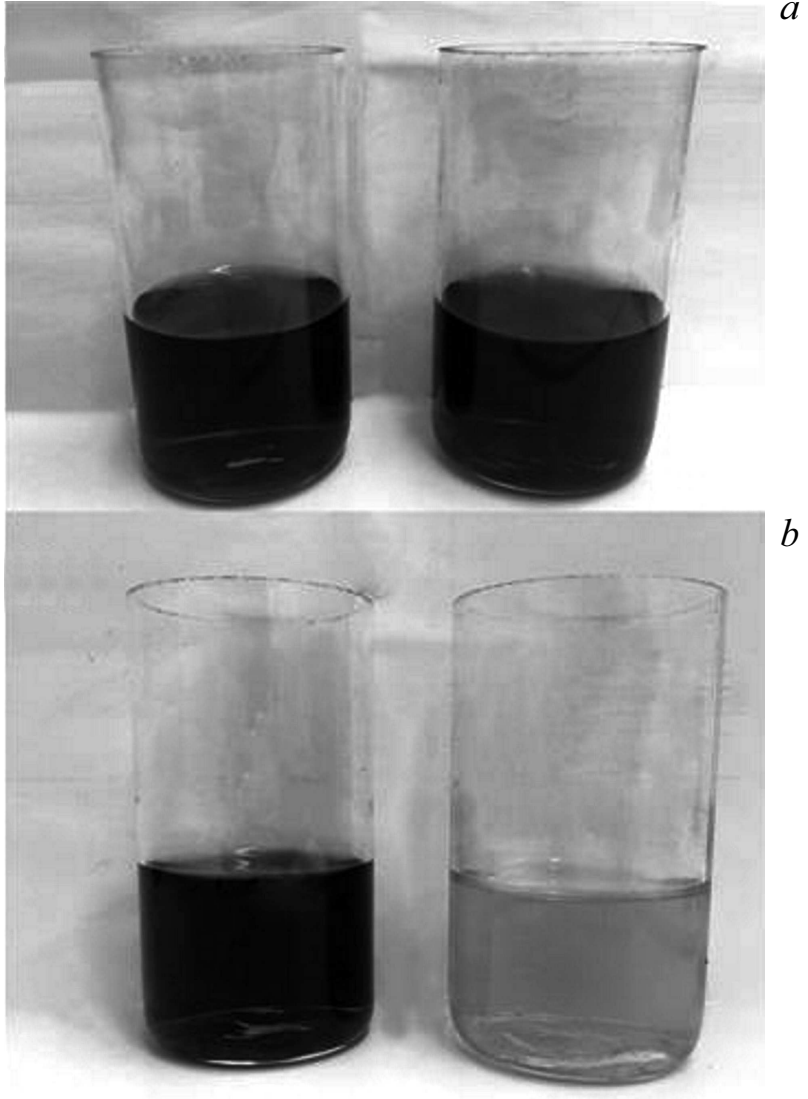

Pис. 4. (а) Фотография раствора CSB без добавок нитратов металлов (слева) и раствора CSB, содержащего нитрат цинка $(0.15 \mathrm{M})$ (справа), до облучения, концентрация CSB в обоих растворах $8.6 \cdot 10^{-6}$ M. (b) Фотография раствора CSB (концентрация $8.6 \cdot 10^{-6} \mathrm{M}$ ) (слева) и раствора CSB (концентрация $\left.8.6 \cdot 10^{-6} \mathrm{M}\right)$, содержащего нитрат цинка $(0.15 \mathrm{M})$ (справа), после облучения ртутной лампой высокого давления в течение $10 \mathrm{~min}$. 
голубым. Аналогичная фотообработка растворов, содержащих нитраты металлов, приводит к резкому изменению их цвета до прозрачного со слабым серым оттенком. Наблюдаемые на фотографиях различия в цвете фотообработанных растворов $\mathrm{CSB}$, содержащих нитраты металлов и без этих солей иллюстрируют различия в их спектрах поглощения (рис. 3). Фотографии показывают также, что фотообработанные растворы, изменяя цвет, сохраняют однородность и прозрачность, что говорит об отсутствии в них каких-либо крупных неоднородностей.

Наиболее просто основной закон фотохимической кинетики может быть выражен следующим уравнением:

$$
-\frac{\partial C}{C} \frac{1}{\partial t}=K \frac{I}{h v}
$$

где $I$ - интенсивность падающего света, $h v-$ энергия фотона, $C$ - концентрация молекул красителя, $K$ - фоточувствительность данной системы [14]. При использовании в эксперименте стабильного источника излучения значение $I / h v$ в правой части уравнения (1) является постоянным. При неизменности величин $K$ и $I / h v$ концентрация красителя в ходе фотохимической реакции изменяется экспоненциально.

На рис. 5, а приведены кинетические зависимости фотолиза CSB в водных растворах различной концентрации, не содержащих нитраты металлов. Из рисунка видно, что УФ облучение водных растворов приводит к постепенному разложению красителя (рис. $3, a$ ). Практически полное разложение красителя наблюдается после 60 min облучения.

Процессы фотолиза растворов CSB c добавками нитратов металлов протекают значительно быстрее (рис. 5,b). При облучении растворов в течение уже первых $15 \mathrm{~min}$ основная часть содержащегося в них красителя разлагается. Это явление наблюдается как при наличии в растворе только нитрата цинка, так и в присутствии в растворе смеси нитратов цинка и иттрия.

Следует отметить, что процессы фотообработки растворов CSB, кроме разложения молекул красителя и образования продуктов фотохимической реакции, могут приводить к изменению процессов межмолекулярного взаимодействия (например, к распаду димеров и тримеров молекул красителя) и образованию комплексов с ионами металлов. Различия в характере и кинетике изменения спектральных свойств растворов CBS, содержащих только этот краситель, и растворов CBS, в которых дополнительно присутствуют нитраты металлов, могут также определяться частичным фоторазложением анионов $\mathrm{NO}_{3}^{-}$. Процессы разложения этих анионов при УФ облучении водных растворов, содержащих нитраты, были описаны ранее в [2,3]. По данным [2] при этом протекают следующие фотохимические реакции:

$$
\begin{gathered}
\mathrm{NO}_{3}^{-}+h v \rightarrow \mathrm{NO}_{2}^{-}+\mathrm{O} \\
\mathrm{NO}_{3}^{-}+h v \rightarrow \mathrm{NO}_{2}+\mathrm{O}^{-}
\end{gathered}
$$
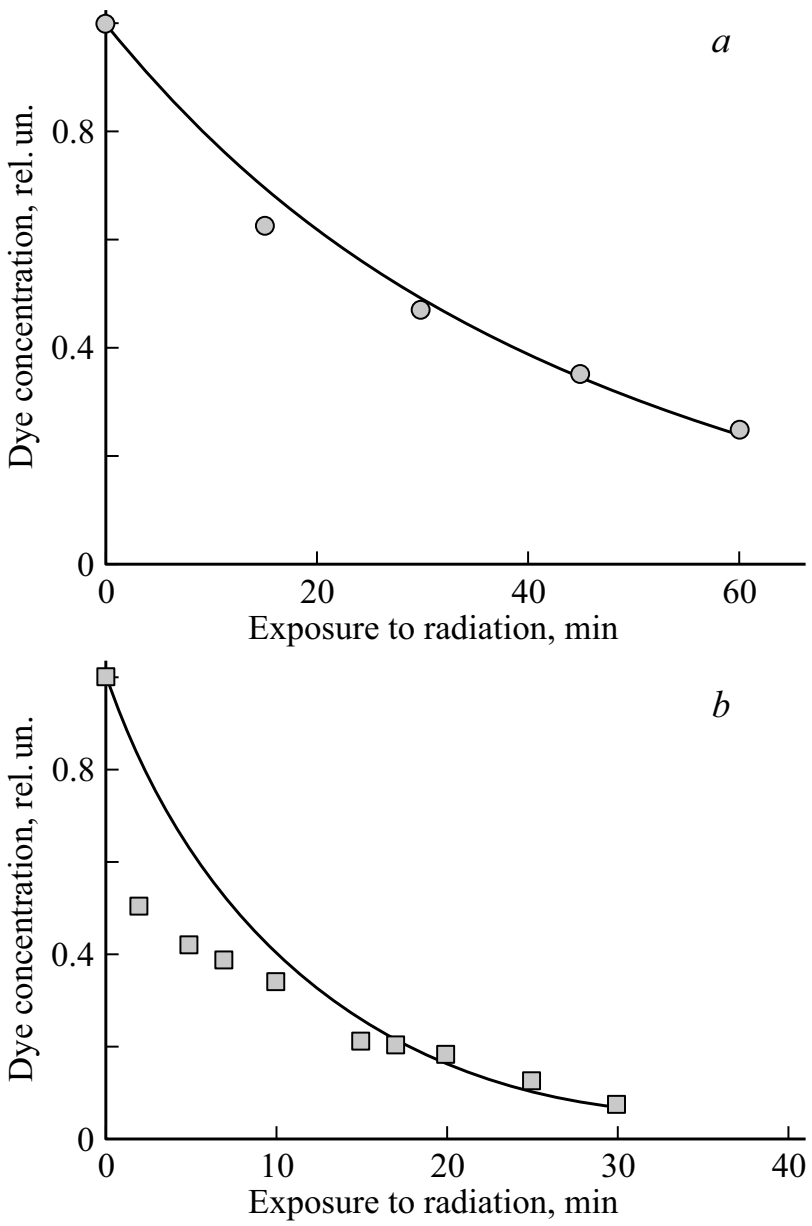

Рис. 5. Кинетики изменения относительного содержания CSB при УФ облучении в растворе, не содержащем нитраты металлов $(a)$, и в растворе, содержащем нитраты цинка $(0.15 \mathrm{M})$ и иттрия $\left(6.5 \cdot 10^{-3} \mathrm{M}\right)(b)$. Фиттинг экспонентой: $(a) y=\exp (-0.02 x), R^{2}=0.984 ;$; $\left.b\right) y=\exp (-0.09 x)$, $R^{2}=0.866$.

Продукты фоторазложения анионов $\mathrm{NO}_{3}^{-}$могут, в свою очередь, участвовать в разложении органических соединений [3]. Это может быть причиной наблюдаемого существенного ускорения разложения в растворе диазокрасителя в присутствии нитратов металлов.

Сопоставление спектров поглощения исходных и подвергнутых УФ облучению ртутной лампой в течение $40 \mathrm{~min}$ растворов нитратов металлов, не содержащих краситель, не обнаружило сколько-нибудь заметного различия между ними. Это позволяет сделать вывод о том, что при использованных условиях облучения степень разложения нитратов мала. Однако, учитывая, что молярное содержание ионов $\mathrm{NO}_{3}^{-}$в смешанных растворах существенно выше, чем молекул красителя, фоторазложение даже относительно малой доли нитратов может приводить к наблюдаемым существенным.

Из рис. 5 видно, что экспоненциальные зависимости неудовлетворительно описывают экспериментально наблюдаемую кинетику фотолиза CSB в водных растворах, 
что может быть связано с возникновением при фотолизе продуктов, поглощающих УФ излучение. Присутствие в водном растворе CSB нитратов металлов дополнительно усложняет кинетику фотолиза красителя под действием УФ излучения ртутной лампы.

\section{Выводы}

Экспериментально показано, что присутствие нитратов цинка и иттрия в водных растворах диазокрасителя Chicago Sky Blue существенно изменяет характер эволюции спектральных свойств и увеличивает скорость фотохимического разложения красителя под действием УФ излучения. Экспоненциальные зависимости неудовлетворительно описывают экспериментально наблюдаемую кинетику фотолиза CSB в водных растворах.

\section{Список литературы}

[1] Guldin S., Kohn P., Stefik M., Song J., Divitini G., Ecarla F., Ducati C., Wiesner U., Steiner U. // Nano Letters. 2013. V. 13. P. 5329-5335.

[2] Warneck P., Wurzinger C. // J. Phys. Chem. 1988. V. 52. P. $6278-6283$.

[3] Minero C., Chiron S., Falletti G., Maurino V., Pelizzetti E., Ajassa R., Carlotti M.E., Vione D. // Aquatic Sciences. 2007. V. 69. P. $71-85$.

[4] Киселев В.М., Евстропьев С.К., Стародубцев А.М. // Опт. и спектр. 2017. Т. 123. № 5. С. 798-805. Kiselev V.M., Evstropiev S.K., Starodubtsev A.M. // Opt. Spectr. 2017. V. 123. N 5. P. $809-815$.

[5] Chatterjee D., Dasgupta S. // J. Photochem. Photobiol. C. 2005. V. 6. P. $186-205$.

[6] Brown G.T., Darwent J.R. // J. Chem. Soc. Faraday Transactions 1. 1984. V. 80. P. 1631-1643.

[7] Mohamed R.M., Mkhalid I.A., Al-Thabaiti S.A., Mokhtar Mohamed // J. Nanosci. Nanotechnol. 2013. V. 13. P. 4975-4980.

[8] Othman I., Tabet M., Farag A. // J. Int. Envir. Appl. Sci. 2012. V. 7. P. $661-672$.

[9] El-Bahy Z.M., Ismail A.A., Mohamed R.M. // J. Hazardous Mater. 2009. V. 166. N 1. P. $138-143$.

[10] Zulkarnain Zainal, Lee Kong Hui, Mohd Zobir Hussein, Yun Hin Taufiq-Yap, Abdul Halim Abdullah, Irmati Ramli // J. Hazardous Mater. 2005. V. 125. P. 113-120.

[11] Abbott L.C., Batchelor S.N., Oakes J., Lindsay Smith J.R., Moore J.N. // J. Phys. Chem. B. 2004. V. 108. P. $13786-13735$.

[12] Zavastin D.E., Gherman S., Cretescu I. // Revista de Chimie. 2012. V. 63. P. 1075-1078.

[13] The Chemistry of Synthetic Dyes.V.3. / Ed. by Venkataram K.N.Y., London: Academic Press Inc., 1974. P. 131-240. Перевод: Химия синтетических красителей. Т. 3. / Под ред. К. Венкатарана. Л.: Химия, 1974. 464 с.

[14] Теренин А.Н. Фотохимия красителей и родственных органических соединений. М., Наука, 1967. С. 101. 